\title{
Improvement of the Thermal Properties of Cement Mortars by Adding Banana Pseudo-Trunkfibres
}

\author{
Pondi Joseph ${ }^{1,2 *}$, Souck Joseph ${ }^{1,2}$, Carlos Mozer ${ }^{1,2}$, Tchotang Theodore ${ }^{2}$, Nyame Boade Wilfried ${ }^{1}$ \\ ${ }^{1}$ Local Materials Promotion Authority (MIPROMALO), Yaoundé, Cameroon \\ ${ }^{2}$ Laboratory of Engineering Civil and Mechanical, Department of Industrial and Mechanical Engineering, University of Yaoundé I, \\ Yaoundé, Cameroon \\ Email: *yannickpondi@gmail.com
}

How to cite this paper: Joseph, P., Joseph, S., Mozer, C., Theodore, T. and Wilfried, N.B. (2020) Improvement of the Thermal Properties of Cement Mortars by Adding Banana Pseudo-Trunkfibres. Open Journal of Civil Engineering, 10, 175-186. https://doi.org/10.4236/ojce.2020.103015

Received: June 8, 2020

Accepted: July 20, 2020

Published: July 23, 2020

Copyright $\odot 2020$ by author(s) and Scientific Research Publishing Inc. This work is licensed under the Creative Commons Attribution International License (CC BY 4.0).

http://creativecommons.org/licenses/by/4.0/ (c) (i) Open Access

\begin{abstract}
The present work examined the influence on thermal properties of the incorporation of banana pseudo-trunkfibres in a cementitious matrix mortar that can be used as rendering or masonry block. The banana pseudo-trunkfibres are extracted, cut and characterized. Then the mortars are made with different proportions of fibres and characterized in order to identify the parameters influencing the characteristics of the material, both in the fresh and hardened state. The physical, mechanical and thermal tests carried out have shown an increase in the porosity and water absorption of the mortar with a decrease in the density, thus making the mortar lighter. It was also noted a decrease in the mortar's flexural and compressive strengths as a function of the percentage of fibres; nevertheless, the values remain within an acceptable range.
\end{abstract}

\section{Keywords}

Fibre, Mortar, Thermal Properties, Pseudo-Trunk

\section{Introduction}

The building sector is nowadays obliged to propose new solutions for the design and rehabilitation of buildings [1]. These new solutions must be more efficient and environmentally friendly [2]. Materials based on plant fibres seem to be the ones that increasingly meet these criteria. Several researches are already being conducted on these materials according to the desired characteristics:

When plant fibres are added to a mortar, they modify the load at the appearance of the first crack. Once the first crack appears, the fibres limit its propaga- 
tion [3]. Thus, long banana fibres increase the durability of a bio composite [4].

Mazhoud [5] and Chabannes [6] showed the hygrothermal efficiency of hemp concretes. In the same vein, Osseni [7] demonstrated that mortars containing banana fibres have a low thermal conductivity. Studies carried out on composite materials incorporating raw plant fibres show a modification of the mechanical behaviour of the material [3]. For example, the mechanical properties of compressed earth blocks were improved by the addition of banana fibres [8] [9]. Similarly, the characteristics of oil palm broom short fibre concretes show that they can be used as roof tile, cladding, lintel beam, and building brick. Sawsen et al. [10] have also shown that the treated linen fibres improve the mechanical characteristics of the mortar. These few studies have shown that plant fibres can be well valorized in a mortar and give it the best properties for a sustainable construction. The problem in our study is therefore to enhance the value of banana pseudo-trunkfibres in a cementitious mortar and to show that the new mortar obtained has good thermal properties. Indeed, since 2015, Cameroon has been the leading banana producer serving African, Caribbean and Pacific (ACP) countries [11]. The waste produced by banana cultivation (particularly the pseudo-trunk) is used as compost, but most often left in the wild. This waste is therefore a local resource to be valorised. The aim of this study is therefore to examine the influence on thermal properties of the incorporation of banana pseudo-trunkfibres in a cementitious matrix mortar that can be used as rendering or masonry block. $\mathrm{NaOH}$ treatment was also done to see its effectiveness on the mechanical properties of the final mortar.

\section{Materials and Methods}

\subsection{Origin Preparation of Banana Pseudo Trunk}

The banana pseudo trunkfibres used in this study come from Cameroon. The fibres were obtained by combing; using a wire brush passed over the concentric layers of pseudo trunk. The banana pseudo-trunk, as well as the fibres obtained, is presented in Figure 1.

\subsection{Fibre Tests}

\subsubsection{Density}

The absolute density of the fibres was measured using a helium pycnometer [12]. This test was necessary because it allows to determine the volume of fibre to be inserted in the mortar according to the percentage (Figure 2).

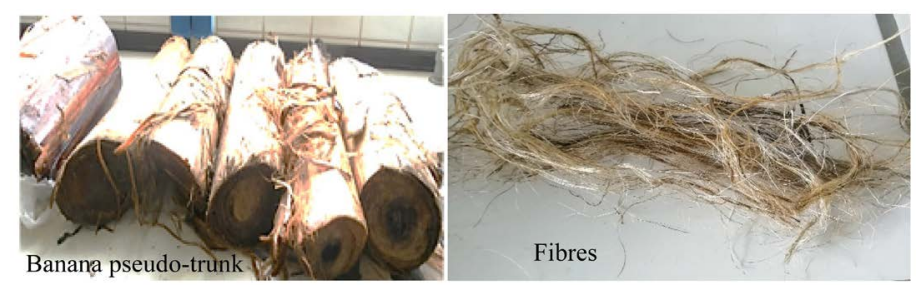

Figure 1. Presentation of banana pseudo-stem and fibers. 


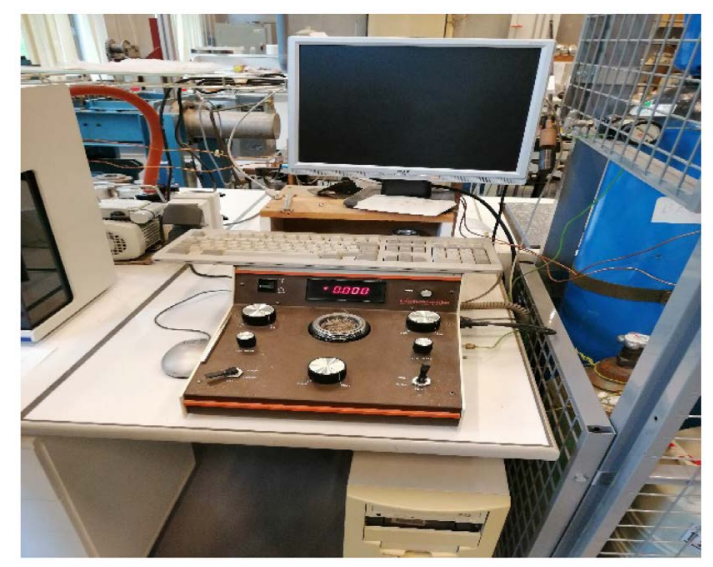

Figure 2. Determination of the density of the fibres by helium pycnometer.

\subsubsection{Recovery Rate}

This test was carried out using the modified protocol according to Davina [13]. A sample of fibres is dehydrated for 3 hours in an oven at $105^{\circ} \mathrm{C}$. Once the 3 hours have passed, and the mass $\left(M_{s}\right)$ constant, the sample is placed in a room under a controlled atmosphere. Every fifteen minutes, the sample is weighed, until two successive equal weightings are obtained. This last value $\left(M_{h}\right)$ constitutes the wet mass of the sample, from which the recovery rate is calculated, using Equation (1):

$$
R \%=\frac{M_{h}-M_{s}}{M_{s}}
$$

\subsubsection{Fibre Treatment with $\mathrm{NaOH}$}

It should be noted that part of the fibres were washed for approximately three hours in a $\mathrm{NaOH}$ solution diluted to $6 \%$, with a normal concentration $(1 \mathrm{~N})$, in the proportions of $1 \mathrm{~g}$ of the fibres per $10 \mathrm{ml}$ of heated water. Beforehand at $120^{\circ} \mathrm{C}$. The purpose of this treatment was to see if the treated fibres improve the mechanical properties better than the untreated fibres.

\subsection{Experiments on the Mortar}

\subsubsection{Determination of the Mass of Fibres Corresponding to Each Combination}

Let $\rho_{f}$ be the density of the fibers; $V$ the volume of the test piece and $X$ the volume percentage of the fibers relative to the volume of the test piece. The corresponding mass for each volume fraction is given by the following Equation (2):

$$
M_{f}=\rho_{f} * V * X
$$

In our case, we worked with four different percentages; so $X$ took the values: $0.5 \%, 1 \%, 1.5 \%$ and $2 \%$. The dimensions of the fibres used in this study are as follows: length $15 \mathrm{~mm}$, average diameter: $0.9 \mathrm{~mm}$.

\subsubsection{Preparation and Making of Test Pieces}

The mixing protocol established in this study and adapted to the fibres is based 
on the EN 196-1 [14] standard. This protocol is as follows:

- Add cement and water to the mixer and mix for thirty seconds at a slow speed;

- Addition of dry fibres and mixing for thirty seconds at a slow speed;

- Adding sand, mixing for thirty seconds at a slow speed; then mixing for another thirty seconds at a fast speed.

- Stopping the mixer and hand kneading for thirty seconds, then resting for one minute; then kneading for one minute at a fast speed.

\subsubsection{Density and Occluded Air}

The density of the fresh mortar was calculated from the weighing of the moulds filled after casting using a balance. The occluded air was calculated using Equation (3) [3].

$$
\text { occluded air }(\%)=100 *\left(1-\rho_{f r} * \frac{\sum V_{i}}{\sum V_{i} * \rho_{i}}\right)
$$

With: $\rho_{f r}$ the density of mortars in the fresh state; $V_{i}$ the volume proportion of component « $i »$ in the mixture; $\rho_{i}$ la density of the constituent " $i$ ".

\subsubsection{Consistency of Mortars}

The workability of the mortars was measured with the shaking table in accordance with standard EN 1015-3 [15] (Figure 3).

\subsubsection{Bending and Compression Test}

The bending and compression tests were carried out on the $4{ }^{\star} 4{ }^{\star} 16 \mathrm{~cm}^{3}$ prismatic mortar specimens in accordance with standard EN 196-1 [14] (Figure 4).

\subsubsection{Capillary Absorption}

The capillary absorption tests were carried out in accordance with standard EN-13057 [16] (Figure 5).

\subsubsection{Porosity and Apparent Density}

The measurement of the porosity accessible to water and the apparent density was made by hydrostatic weighing in accordance with standard EN P18-459 [17] and according to [18] (Figure 6).

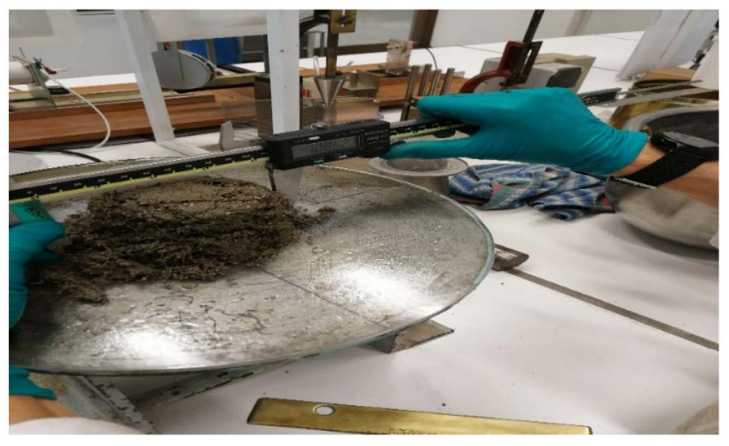

Figure 3. Spreading of mortar containing $2 \%$ of fibers. 


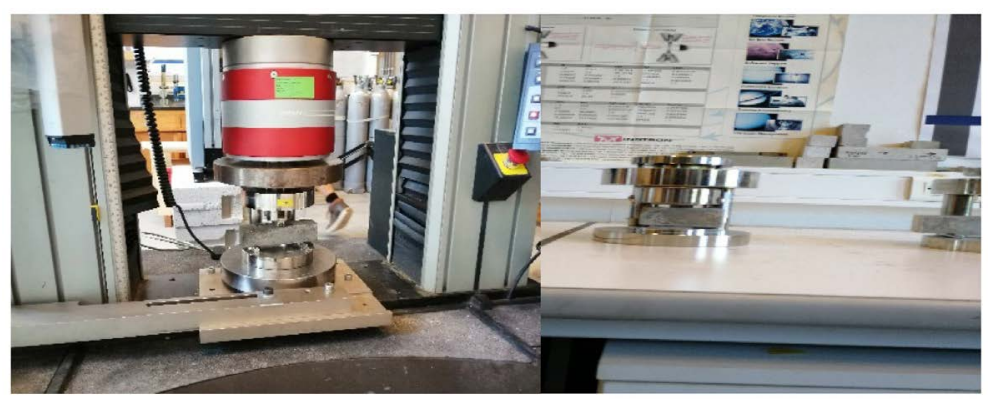

Figure 4. Picture compression and bending test.

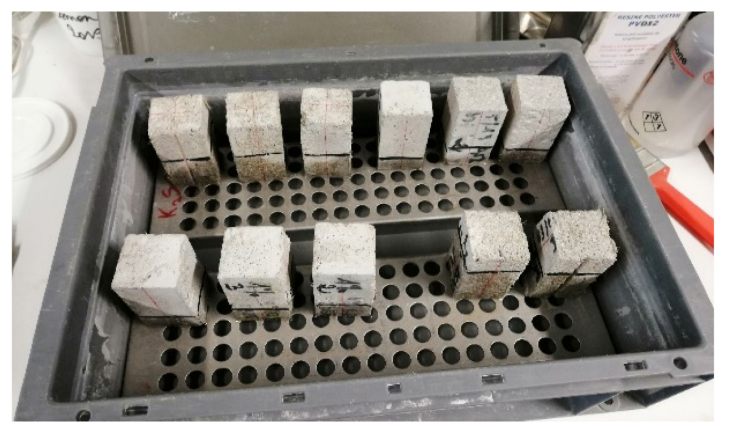

Figure 5. Picture capillary absorption test.

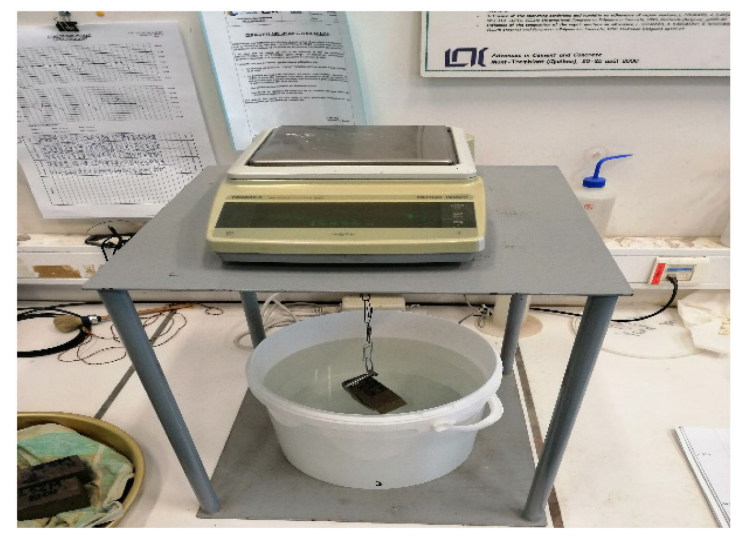

Figure 6. Hydrostatic weighing test.

We can deduce the apparent dry density $\rho_{a}$, and the porosity accessible to water $\varepsilon_{a c c}$, using Equations (4) and (5) respectively:

$$
\begin{gathered}
\rho_{a}=\frac{m_{\text {sec }}}{m_{\text {air }}-m_{\text {eаu }}} * \rho_{\text {еаи }} \\
\varepsilon_{\text {acc }}=\frac{m_{\text {air }}-m_{\text {sec }}}{m_{\text {air }}-m_{\text {eau }}} * 100
\end{gathered}
$$

- $m_{\text {eаu }}$ the mass of the saturated mortar in the suspension system of the hydrostatic balance after immersion for 48 hours (g);

- $m_{\text {air }}$ the mass of the mortar in saturated dry surface conditions (g);

- $m_{\text {sec }}$ the mass of the dried mortar at $(105 \pm 5)^{\circ} \mathrm{C}(\mathrm{g})$. 


\subsubsection{Thermal Conductivity}

The thermal conductivity test was carried out using the hot wire method based on standards ASTM D5334-00 and D5930-97 described after Department of Architecture, Geology, Environment and Construction (ARGENCO) [19] (Figure 7).

\subsubsection{Grip by Direct Traction}

The grip measurement by direct traction was determined according to standard EN 1542 [20] (Figure 8).

\section{Results}

\subsection{Fibre Results}

We obtained an average density of $1.42 \mathrm{~g} / \mathrm{cm}^{3}$, which corresponds well to the order of magnitude of the densities of vegetable fibres. The fibre recovery rate found is around 7\%, this is due to the hemicellulose rate [3]. The corresponding mass for each formulation is given in Table 1.

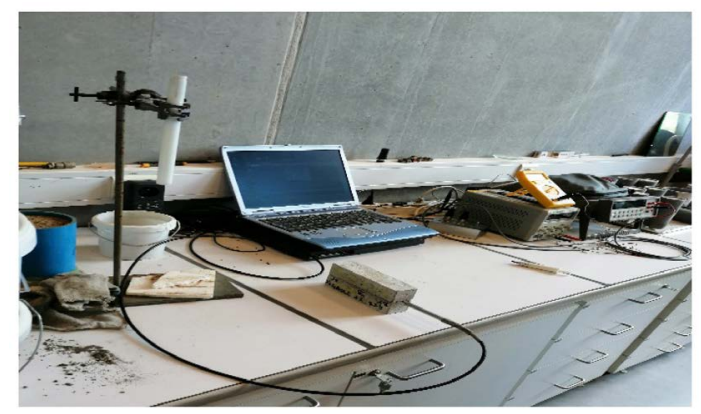

Figure 7. Thermal conductivity with hot wire.

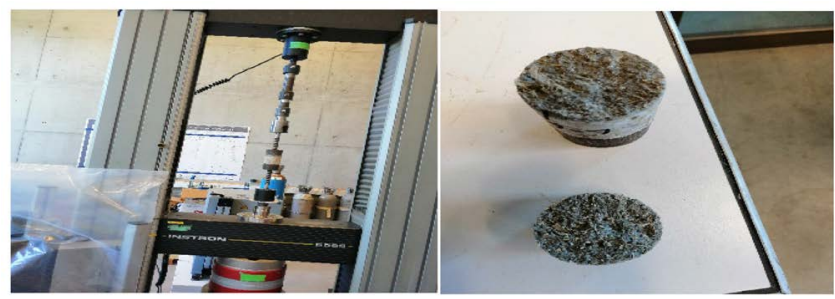

Figure 8. Picture for grip by direct traction.

Table 1. Mass corresponding to each percentage of fibres.

\begin{tabular}{ccccc}
\hline $\begin{array}{c}\text { Percentage } \\
\text { of fibres }\end{array}$ & $\begin{array}{c}\text { Mass of fibres } \\
\text { in grams }(\mathrm{g})\end{array}$ & $\begin{array}{c}\text { Cement mass } \\
\text { in grams }(\mathrm{g})\end{array}$ & $\begin{array}{c}\text { Mass of water } \\
\text { in grams }(\mathrm{g})\end{array}$ & $\begin{array}{c}\text { Mass of sand } \\
\text { in grams }(\mathrm{g})\end{array}$ \\
\hline $\mathbf{0 \%}$ & 0 & 450 & 225 & 1350 \\
$\mathbf{0 . 5 \%}$ & 5.45 & 450 & 250 & 1350 \\
$\mathbf{1 \%}$ & 10.9 & 450 & 250 & 1350 \\
$1.5 \%$ & 16.36 & 450 & 250 & 1350 \\
$2 \%$ & 21.81 & 450 & 250 & 1350 \\
\hline
\end{tabular}




\subsection{Results on Fresh and Hardened Mortar}

\subsubsection{Apparent Density and Air Entrained in Fresh Mortar}

The results obtained from Table 2 show that the more the amount of fibres increases, the greater the content of occluded air and the lower the density. This is due to the moisture uptake rate of the fibres. Other authors have also pointed out the increase in occluded air and the decrease in density as a function of fibre content. This is mainly due to the low capacity of the fibres to compact [21] [22] [23]. This can also be explained by the increase in the void quantity.

\subsubsection{Consistency of Mortars}

The consistency of mortars gradually decreases as the amount of fibre present in the mortar increases; this is due to a loss of handling. This trend was also observed by [24]. Consistency of mortars is almost zero at $2 \%$ fibre; because of their great flexibility, the pseudo banana trunkfibres tend to form pellets during kneading when they are in very large quantities [25] [26]; this is the reason why in the rest of our work we did not work much with mortars containing $2 \%$ fibre (Figure 9).

\subsubsection{Results of Flexural and Compression Tests}

The values of average compressive strengths and flexural strengths of the mortars studied after 28 days of cure are shown in Figure 10. There is a decrease in the compressive strength of the mortar as the percentage of fibres increases. These decreases in resistance have also been pointed out by other authors [3] [27]. In terms of flexural strengths, there has been a "sawtooth" development. This is due to the method of extracting the fibres used which is combing.

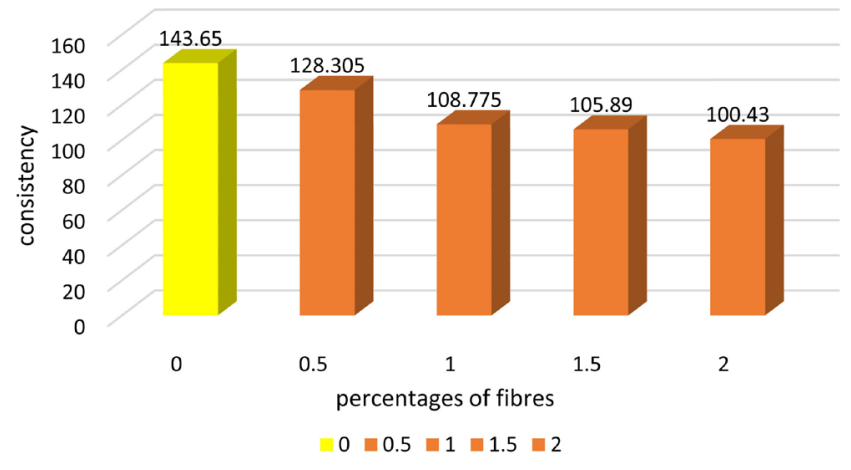

Figure 9. Consistency of mortar.

Table 2. Occluded air and density of fresh mortars.

\begin{tabular}{ccc}
\hline Percentage of fibres & Apparent Density $\left(\mathrm{g} / \mathrm{cm}^{3}\right)$ & Occluded air \\
\hline $0.5 \%$ & 2.22 & 1.57 \\
$1 \%$ & 2.2 & 2.30 \\
$1.5 \%$ & 2.1 & 6.60 \\
$2 \%$ & 1.87 & 16.70 \\
\hline
\end{tabular}



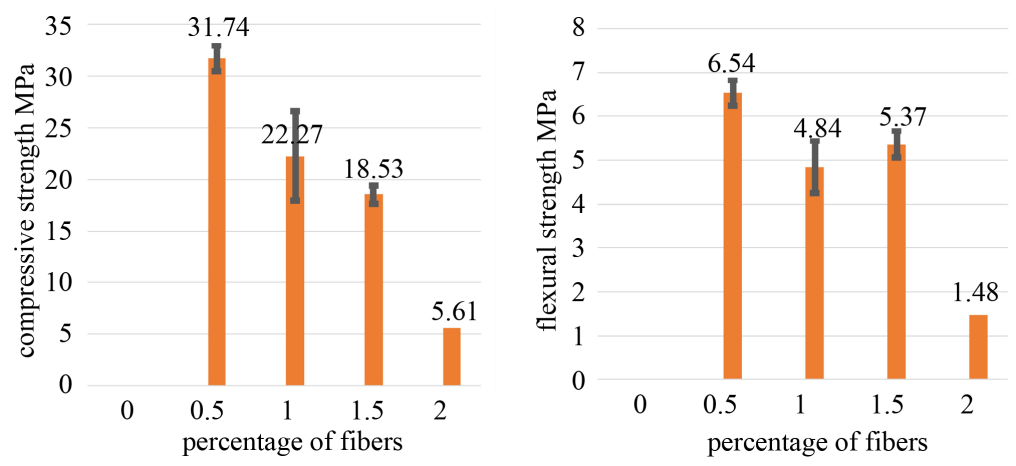

Figure 10. Flexural and compression results as a function of the percentage of fibers.

We also tried to treat a certain quantity of fibres with $\mathrm{NaOH}$ to see if their incorporation in the mortar improves the mechanical characteristics of the mortar. We have observed that for a low percentage of fibres, fibres treated with $\mathrm{NaOH}$ improve the compressive strength of the mortar but not the flexural strength; this is illustrated in Figure 11.

Capillary absorption results

The capillary absorption of fibre mortars varies significantly depending on the percentage of fibres in the mortar as can be seen in Figure 12. The value is minimum for the mortar containing $0.5 \%$ of fibres $1.2 \mathrm{~kg} \cdot \mathrm{m}^{-2} \cdot \mathrm{h}^{-0.5}$ and maximum $1.52 \mathrm{~kg} \cdot \mathrm{m}^{-2} \cdot \mathrm{h}^{-0.5}$ for mortar containing $2 \%$ fibre.

The capillary absorption increases with the fibre content in the mortar this phenomenon is due to the pores created by the fibres in the mortar.

\subsubsection{Results on Porosity and Density of Hardened Mortar}

The results obtained show an increase in porosity with the percentage of fibres in the mortar. It should also be noted that an increase in porosity leads to a decrease in the density of the mortar. Other authors have also noted this relationship [3] (Figure 13).

\subsubsection{Results on the Thermal Conductivity of the Mortar}

We notice a decrease in thermal conductivity as a function of the increase in fibres in the mortar. The more fibre-reinforced the mortar, the better it is a good thermal insulator. This is due to the porosity of the mortar which increases with the amount of fibre (Figure 14).

We can therefore conclude at this stage that the pseudo banana trunkfibres improve the thermal properties of a cement mortar, making it more insulating.

\subsubsection{Results on Adhesion by Direct Traction}

We note a decrease in adhesion with the percentage of fibres in the mortar. This is due to the weak cohesion of fibre mortars. But these values remain acceptable as shown in Figure 15; which means that this mortar can easily be used as a coating up to $1.5 \%$ fibre.

Adhesion greater than or equal to $0.7 \mathrm{MPa}$ is acceptable for a mortar incorporated with fibres which can be used as a rendering. 

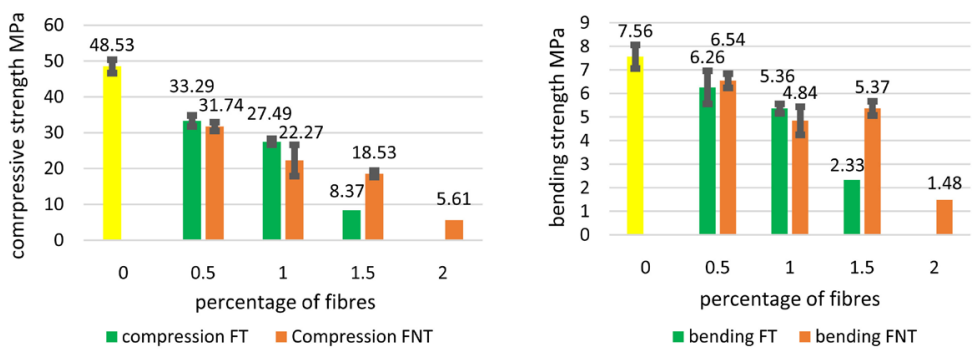

Figure 11. Compression and bending strength of the mortar containing treated fibres (FT) and untreated fibres (FNT).

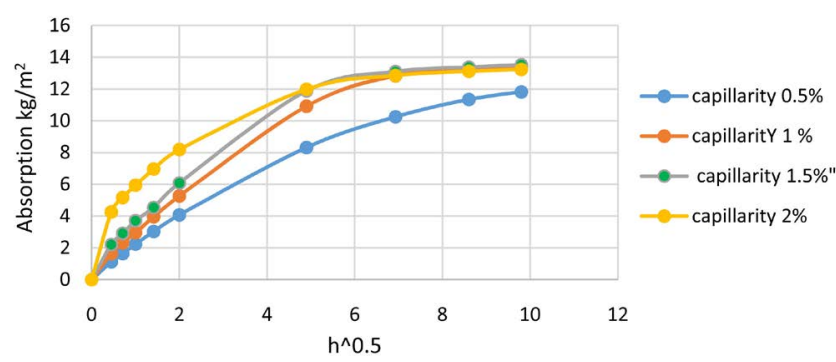

Figure 12. Capillary absorption according to the percentage of fibres.
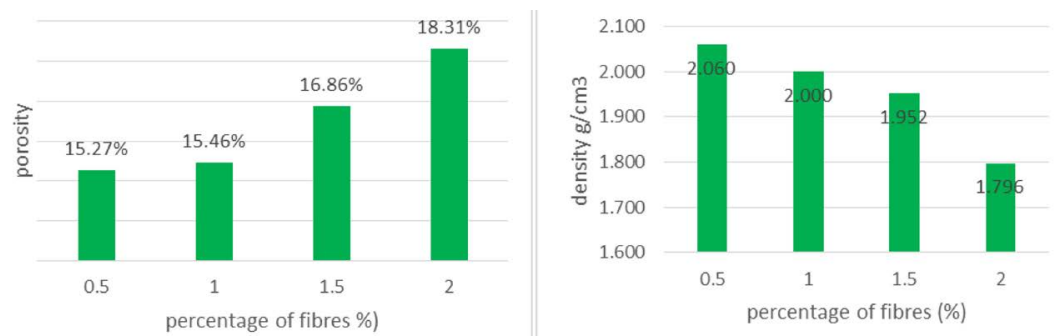

Figure 13. Porosity and density of the mortar as a function of the percentage of fibers.

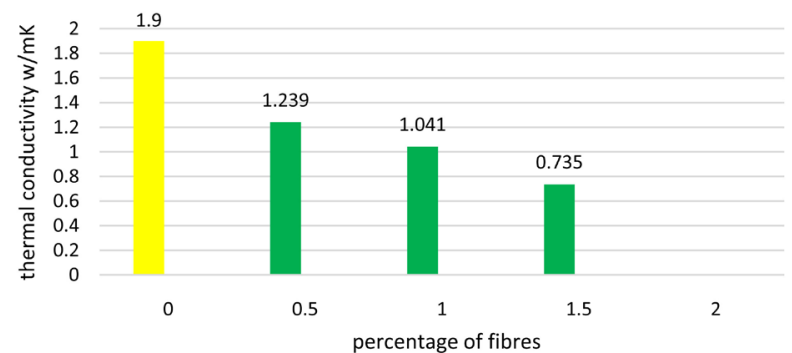

Figure 14. Thermal conductivity of fibre mortars.

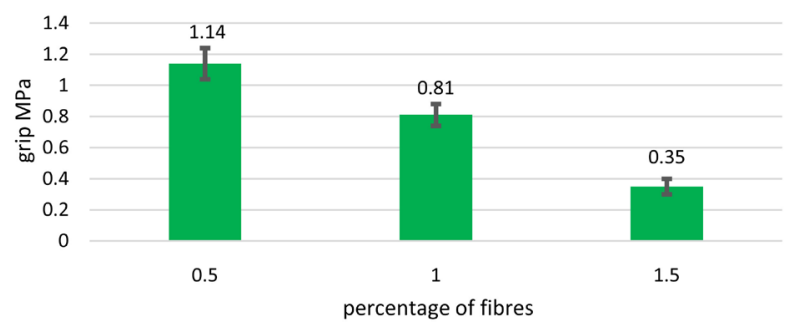

Figure 15. Evolution of adhesion as a function of the percentage of fibres. 


\section{Discussions}

We have presented the experiments carried out in the laboratory as well as the various results relating to them. Some conclusions can be drawn: Mortars containing pseudo trunk banana fibres have mechanical properties in bending and compression, weaker than the reference mortar, this is closely linked to the method used to extract the fibres and to the dimensions of the latter. However, they have rather interesting thermal properties due to the lower thermal conductivity when the percentage of fibres is high. The fibres treated with $\mathrm{NaOH}$ slightly improve the mechanical properties (compressive strength) of the mortars but always remain below the properties of the reference mortar. The banana pseudo-trunkfibres incorporated in the mortar increase the porosity of the latter and make it lighter. Given the results obtained, we intend to conduct a study soon on the influence of the length and the extraction process of these fibres in the mortar. Tests on shrinkage must also be carried out in order to know if these fibres are capable of limiting the propagation of cracks in the mortar.

\section{Conclusions and Recommendations}

All of the work presented here has been carried out at the Laboratory of Building Materials at the University of Liège. The objective of this work was to study the mechanical, physical and thermal behaviour of mortars with cementitious matrices of pseudo trunk banana fibre that can be used as plaster or as a masonry block. To achieve this, we have reviewed several research studies relating to the incorporation of plant fibres in a cement matrix composite. It appears that, the vegetable fibres as a function of their characteristics, improve the mechanical, thermal and physical characteristics of composites with a cement matrix. After this bibliographical synthesis we carried out a certain number of laboratory tests on fibres, and on mortars in the fresh and hardened state. The fibres were cut to a length of $15 \mathrm{~mm}$, then dried in an oven at $105^{\circ} \mathrm{C}$. Parts of the fibres were washed in a solution of $\mathrm{NaOH}$ diluted to $6 \%$. The incorporation of these fibres in the mortar has changed its physical, mechanical and thermal properties.

Fibre mortars had a porosity of $15.27 \%$ to $18.31 \%$; and an occluded air content $1.57 \%$ to $15.37 \%$. Mechanical characteristics: compressive strength from 31.74 to $5.61 \mathrm{MPa}$; flexural strength of 6.54 to $1.48 \mathrm{MPa}$ and the tensile adhesion of 1.14 to $0.35 \mathrm{MPa}$ of the new material obtained are lower, due to the low tensile strength of the fibres, but remain satisfactory. The thermal conductivity of the new material is rather low, up to $0.7 \mathrm{~W} / \mathrm{mK}$ which gives it a good thermal insulation characteristic.

Since this work will have to be implemented, the new material that we want to put in place will have to be used. We recommend the use of mortar with $0.5 \%$ and $1 \%$ fibre as a plaster or masonry blocks; and mortar with $1.5 \%$ fibre as masonry block only. As we said above, the perspectives that open up to such work are among others:

- The in-depth study of the effect of the different treatments of pseudo trunk 
banana trunkfibres on the thermo-physical properties of the mortar;

- The study of shrinkage as a function of the percentage of fibres in the mortar;

- The study of the influence of the length of the fibres and the method of extracting them on the physical, mechanical and thermal properties of the mortar.

\section{Conflicts of Interest}

The authors declare no conflicts of interest regarding the publication of this paper.

\section{References}

[1] Magniont, C. (2010) Contribution à la formulation et à la caractérisation d'un écomatériau de construction à base d'agroressources. PHD Thesis, University of Toulouse III-Paul Sabatier, Toulouse, $343 \mathrm{p}$.

[2] Glé, P. (2013) Acoustique des matériaux du bâtiment à base de fibres et particules végétales-outils de caractérisation, modélisation et optimisation. PHD Thesis, INSA of Lyon, Lyon, 389 p.

[3] Page, J. (2017) Formulation et caractérisation d'un composite cimentaire bio fibré pour des procédés de construction préfabriquée. PHD Thesis, University of Caen Normandie, Caen, 240 p.

[4] Sango, T., Yona, C.M.A., Duchatel, L., Marin, A., Ndikontar, K.M., Joly, N. and Lefebvre, M.J. (2018) Step-Wise Multi-Scale Deconstruction of Banana Pseudo-Trunk (Musa acuminata) Biomass and Morpho-Mechanical Characterization of Extracted Long Fibres for Sustainable Applications. Industrial Crops and Products, 122, 657-668. https://doi.org/10.1016/j.indcrop.2018.06.050

[5] Mazhoud, B. (2017) Elaboration et caractérisation mécanique, hygrique et thermique de composites bio-sourcés. PHD Thesis, University of Bretagne, Loire, 212 p.

[6] Chabane, M. (2015) Formulation et étude des propriétés mécaniques d'agrobétons légers isolants à base de balles de riz et de chènevotte pour l'éco-construction. $\mathrm{PHD}$ Thesis, University of Montpellier, Montpellier, $226 \mathrm{p}$.

[7] Osseni, S.O. (2017) Formulation et caractérisation thermomécanique de mortiers renforcés par des fibres du tronc de bananier. PHD Thesis, University of Abomey-Calavi, Benin, 148 p.

[8] Amir, N., Abidin, Z.A.K. and Shiri, B.F. (2017) Effects of Fibre Configuration on Mechanical Properties of Banana Fibre/PP/MAPP Natural Fibre Reinforced Polymer Composite. Procedia Engineering, 184, 573-580. https://doi.org/10.1016/j.proeng.2017.04.140

[9] Mostafa, M. and Uddin, N. (2016) Experimental Analysis of Compressed Earth Block (CEB) with Banana Fibers Resisting Flexural and Compression Forces. Case Studies in Construction Materials, 5, 53-56. https://doi.org/10.1016/j.cscm.2016.07.001

[10] Sawsen, C., Fouzia, K., Mohamed, B. and Moussa, G. (2014) Optimizing the Formulation of Flax Fiber-Reinforced Cement Composites. Construction and Building Materials, 54, 659-664. https://doi.org/10.1016/j.conbuildmat.2013.12.038

[11] Djotié, J.L. (2016) le quotidian de l'économie. http://www.camer.be/56448/12:1/agriculture-le-cameroun-devient-premier-product eur-de-banane-acp-cameroon.html 
[12] Department of Architecture, Geology, Environment and Construction (ArGEnCo) (2001) Geotechnology Laboratory. Gas Pycnometer (Helium): Determination of the Density of Grains Based on the Standard NF EN ISO 8130-2. 1 p.

[13] Davina, M. (2013) Evaluation du potentiel fibreux et textile de la canne à sucre (Saccharum officinarum L.). PHD Thesis, University of Haute Alsace, Mulhouse, $187 \mathrm{p}$.

[14] EN 196-1 (2006) Méthodes d'essais des ciments-Détermination des résistances mécaniques.

[15] EN 1015-3 (1999) Méthodes d'essai des mortiers pour maçonnerie-Partie: Détermination de la consistance du mortier frais (à la table à secousse).

[16] EN 13057 (2002) Produits et systèmes pour la protection et la réparation des structures en béton-méthodes d'essai-Détermination de l'absorption capillaire.

[17] EN P18-459 (2010) Béton-Essai pour béton durci-Essai de porosité et de masse volumique.

[18] Dupain, R., Lanchon, R. and Saint-Arroman, J.C. (2000) Granulats, Sols, Ciments et Bétons: Caractérisation des Matériaux de Génie Civil par les Essais de Laboratoire. 2nd Edition, Eleducalivre, Editions Casteilla, Paris, 238 p.

[19] Department of Architecture, Geology, Environment and Construction (ArGEnCo) (1981) Geotechnology Laboratory. Thermal Tests, Needle Diffusion: Determination of the Coefficient of Thermal Conductivity of Materials Based on the Standard ASTM D5334-00 \& D5930-97. 1 p.

[20] EN 1542 (1999) Produits et systèmes pour la protection des structures en béton-Méthodes d'essais-Mesurage de l'adhérence par traction directe.

[21] Gencel, O., Ozel, C., Brostow, W. and Martinez-Barrera, G. (2011) Mechanical Properties of Self-Compacting Concrete Reinforced with Polypropylene Fibres. Materials Research Innovations, 15, 216-225. https://doi.org/10.1179/143307511X13018917925900

[22] Madsen, B., Thygesen, A. and Lilholt, H. (2009) Plant Fibre Composites-Porosity and Stiffness. Composites Science and Technology, 69, 1057-1069.

https://doi.org/10.1016/j.compscitech.2009.01.016

[23] Pickering, K.L., Efendy, M.G.A. and Le, T.M. (2016) A Review of Recent Developments in Natural Fibre Composites and Their Mechanical Performance. Composites Part A: Applied Science and Manufacturing, 83, 98-112. https://doi.org/10.1016/j.compositesa.2015.08.038

[24] Tung, L., Khadraoui, H., Boutouil, M. and Gomina, M. (2012) Caractérisation microstructurale et mécanique d'un composite cimentaire renforcé par des fibres de lin. MATEC Web of Conférences, 2, 8. https://doi.org/10.1051/matecconf/20120201014

[25] Bentur, A. (2007) Fibre Reinforced Cementitious Composites, 2nd Edition. Taylor \& Francis, London, New York. https://doi.org/10.1201/9781482267747

[26] Aziz, M.A., Paramasivam, P. and Lee, S.L. (1981) Prospects for Natural Fibre Reinforced Concretes in Construction. International Journal of Cement Composites and Lightweight Concrete, 3, 123-132. https://doi.org/10.1016/0262-5075(81)90006-3

[27] Chafei, S. (2014) Influence de différents traitements sur les comportements rhéologiques et mécaniques d'un composite cimentaire mortier-fibres de lin. Thesis, University of Caen Basse-Normandie, Caen. 